\title{
Gender Differences in the Prevalence of Electronic Nicotine Product Use Among College Students in the U.S. - Analyses of the 2017 Population Assessment of Tobacco and Health (PATH) Study
}

\section{Michelle Hsia \\ University of Florida}

Faculty Mentor: Catalina Lopez-Quintero, College of Public Health and Health Professions \& College of Medicine

\begin{abstract}
E-nicotine products (ENPs) use among youth and young adults is a major public health concern. The objective of this study was to analyze, among a nationally representative sample of college students in the U.S., gender differences in the lifetime, past 12-months, and past 30-day prevalence of ENPs use, reasons for use, and susceptibility to ENP use among never users. Data from the Population Assessment of Tobacco and Health (PATH) Study were analyzed. The study population included college-aged individuals (18-24 years old) enrolled in a degree program. The results of the study revealed that males were more likely to use ENPs than females. Both males and females reported a high proportion of misconception about ENPs, particularly with regards to ENPs being less harmful to the user than cigarettes. It also indicated that $36 \%$ of male and $32 \%$ of female college students were susceptible to start using ENPs. The results of this study highlight the need to provide comprehensive, tobacco-prevention education among U.S. youth.
\end{abstract}

Keywords: Electronic Nicotine Products, E-cigarettes, Population Assessment of Tobacco and Health Study

\section{Introduction}

Today, ENP use among young adults in U.S., particularly college students, is a major public health concern. In 2016, there were 10.8 million adult ENP users in the U.S., and the prevalence of ENP use was the highest among persons aged 18-24 years old (approximately 2.8 million) (Murthy, 2017). Evidence suggests that the use of ENPs can lead to regular tobacco use and nicotine dependence, which raises concerns as tobacco smoking is currently the most preventable cause of premature death (National Center for Chronic Disease Prevention and Health Promotion, 2014). In the past 50 years, prevalence of cigarette smoking in the U.S. has decreased due to public health education and promotion efforts. However, this progress has been jeopardized by the emergence of ENPs (King et al., 2015) and the respective development of 
highly efficient nicotine delivery products (Bullen et al., 2010). Many studies have shown that use of nicotine may be of particular danger to young adults, as their brains are especially vulnerable to the adverse effects of nicotine exposure including deficits in learning and priming for use of other addictive substances (National Center for Chronic Disease Prevention and Health Promotion, 2014; U.S. Department of Health and Human Services, 2016; Murthy, 2017). Meanwhile, the full health impact of ENPs and the factors that lead to their popularity among young adults requires further study, especially given the nature of rapidly changing products and patterns of use.

Although college campuses across the U.S. are required to be smoke-free and existing college health promotion programs are against cigarette smoking and ENP use (Wang et al., 2018), little is known about ENP use among college students in the United States at the national level. Thus far, existing studies about ENP use among college students have been universityfocused (Ickes et al., 2020; Roberts et al., 2020; Smith et al., 2020; Newcombe et al., 2021), rather than using a nationally representative probability sample. Since the target population of university-based studies is a respective university, the conclusion cannot be generalized. The use of a national probability sample is, therefore, more appropriate for making valid inferences concerning the U.S. nation-wide.

Traditionally, a combination of physiological, cultural, and behavioral factors have contributed to gender differences in tobacco use. Women are more likely to become nicotine dependent and smoking cessation is less likely among women than among men (Smith et al., 2016; Cross et al., 2017; Pogun et al., 2017). A study using a large, population-based survey also showed gender differences, indicating that $16.7 \%$ of male adults and $13.6 \%$ of female adults reported smoking cigarettes (Mirbolouk et al., 2018). Therefore, while studying prevalence of ENP use among college students, it is also important to conduct an epidemiological study of the differences between male and female students.

In 2019, the U.S. Centers for Disease Control and Prevention identified an outbreak of deadly ENP-use associated lung injury, and increasing restrictions on the sales of ENPs and narrowing of the range of flavors available for purchase began (Friedman, 2020). As these changes were implemented prior to 2017, the data garnered from this study can help inform the work of researchers, public health officials, and regulatory authorities seeking to compare ENP use prior to 2019 guideline implementation to ENP use after and, thus, examine efficacy of the 
restriction to decrease ENP use. Understanding gender differences in ENP use among college students is crucial to: 1) fill in a gap of nationwide information, 2) improve the effectiveness of health education programs, and 3) improve public health policy in order to curb a potential epidemic. This study was conducted with the belief that examining whether a gender-specific trend in ENP use exists can help guide public policymakers in the future or aid in adjusting currently existing health promotion programs on U.S. college campuses.

Accordingly, this project analyzes PATH Wave 4 data to estimate the prevalence of lifetime, past 12-months, and past 30-day ENP use separately for male and female college students. Among users, this study characterized the reasons for ENP use, as well as the flavors used when lifetime users first tried ENPs. Susceptibility to ENP use by gender was estimated among never users.

The main purposes of this study were to examine 1) if gender differences existed concerning prevalence of lifetime, past 12-months, and past 30-day ENP use, respectively; 2) whether gender differences existed regarding reasons for ENP use, and 3) if a difference in susceptibility to ENP use between male and female college student never users was present.

\section{Methods}

\section{Data and Study Population}

For this study, researchers used PATH Wave 4 public use data. PATH is a national, population-based longitudinal survey (United States Department of Health and Human Services, 2019). In brief, PATH has collected 5 waves of data from 2013 to November 2019. This project limited the studied population to those age 18-24 years and enrolled in a degree program in 2017. This provided a total of 4333 young adults to approximate college students in the United States. Because PATH was a longitudinal survey, some individuals in the population of interest in Wave 4 had answered whether or not they had ever used ENPs in their lifetime and whether or not they used a flavored ENP product when they first used at the point within Waves $1-4$ that they first entered the study. For example, 18-24 years old individuals in 2013 answered those questions of interests in Wave 1 while individuals who turned into 18 in 2019 answered the questions in Wave 4. In order not to lose this data, researchers used the Case ID of participants in the study to track back data from PATH Wave 1 to 3 . 


\section{Measures}

The outcome variables fell into the following three categories:

ENP use. Current use was defined as past 30-day use for all studied adults. Past 12months use was defined as either past 30-day use or, if not, past 12-months use. As PATH is a longitudinal survey, lifetime ENP use information was collected in all 4 waves and in both adult and youth modules, depending on age of those studied. Liftetime use was ascertained for the studied people who answered "yes" to the questions, "Did you use any electronic nicotine products even one or two times?" in any survey wave or module. For the same reason as lifetime use, flavored of ENPs used when lifetime users first stated was also ascertained for the lifetime users in all waves and modules.

reasons for ENP use. Eight reasons of ENP use among currently or formerly established, current experimental or non-current users were studied. These reasons were: "ENPs were affordable", "ENPs were allowed while cigarettes were not", "ENPs were less harmful to the user than cigarettes", "ENPs were less harmful to people around the user than cigarettes", "Eliquid had flavors the user liked", "Using ENPs helped the user quit cigarettes", "ENPs don't smell", and "ENPs were more acceptable to non-tobacco users".

susceptibility of ENP never users. Susceptibility of ENP never users was measured by responses (definitely yes, probably yes, probably not, and definitely not) to the following three questions: "Do you think that you will try an ENP soon?", "If one of your best friends were to offer you an ENP, would you use it?", and "Have you ever been curious about using ENP?" Only those who responded "definitely not" to all three questions were defined as nonsusceptible.

\section{Covariates}

The following covariates were used in the multivariable analysis: self-identified race/ethnicity (non-Hispanic White, non-Hispanic Black, Hispanic, and non-Hispanic other), type of degree enrolled (technical/vocational, 2-year degree, 4-year degree, graduate/professional, and other type), and region (Northeast, Midwest, South, and West). Other covariates used were dichotomized (yes/no): cigarette smoking and alcohol drinking in the past 12-months, ever use of marijuana (including blunts), misuse of prescription drugs (i.e. Ritalin ${ }^{\circledR}$ or Adderall@; painkillers, sedatives, or tranquilizers), and other drugs (cocaine or crack, stimulants (i.e. methamphetamine or speed), heroin, inhalants, solvents, and hallucinogens). The 
covariate of mental health was assessed via the Global Appraisal of Individual Needs - Short Screener (GAIN-SS), modified for the PATH Study (Dennis, 2006; Conway et al., 2017). The GAIN-SS instrument include 4 internalizing problem items and 7 externalizing problem items. The item measures were across four time periods: past month, 2-12 months ago, over a year ago, and never. The mental health severity was defined by no/low (0-1 symptoms), moderate (2-3 symptoms), or high ( 4 for internalizing problems or $\geq 4$ symptoms externalizing problems) in the past 12-months.

\section{Statistical Analysis}

Analyses were conducted in SAS (SAS Institute, version 9.4) using PATH Wave 4 crosssectional survey weights with balanced repeated replication and Fay's adjustment of 0.3. The total sample was characterized based on the socio-demographic, college related variables, substance use and mental health. Estimates for use, reasons of use, flavors used and susceptibility to use were calculated separately for both males and females. Prevalence was calculated using the procedure of SURVEYFREQ. Prevalence ratios were calculated using the procedure of SURVEYPHREG with a constant time variable, adjusting for race/ethnicity, type of degree enrolled, region, substance use/misuse, and mental health severity. Two sample z-tests were applied in order to examine whether or not a gender difference existed. The estimate was labelled if the relative standard error was greater than $30 \%$. The procedure of SURVEYLOGISTIC was also applied to estimate associations between ENP use and the selected covariates.

\section{Results}

Characteristics of the sample are presented in Table 1. Data from 4333 individuals participating in the PATH study Wave 4, who were 18-24 years old and enrolled in a degree program, were included in this report. The sample included $46.8 \%$ male college students and $53.3 \%$ female college students. Non-Hispanic White students made up the largest percentage of the sample at $55.38 \%$, while non-Hispanic Black students made up the smallest percentage at $12.36 \%$. Among the studied students, more than 1 in 4 smoked cigarettes and more than 3 in 4 drank alcohol in the past 12-months, near half had ever used marijuana, and a quarter had ever misused prescription drugs or used other drugs. Internalizing mental problems among college 
students (30.4\%) were reported to be twice as high as the level of externalizing mental problems $(16.1 \%)$.

Table 1. Distribution of studied sample: Aged 18-24 years and currently enrolled in degree program in the US, 2017

\begin{tabular}{|c|c|c|c|c|}
\hline \multirow{2}{*}{$\begin{array}{l}\text { Variable } \\
\text { Overall }\end{array}$} & \multirow{2}{*}{$\frac{n}{4333}$} & \multicolumn{3}{|c|}{ Weighted Proportion $(\%, 95 \% \mathrm{CI})$} \\
\hline & & 100.00 & & \\
\hline \multicolumn{5}{|l|}{ Gender } \\
\hline Male & 1995 & 46.77 & (45.30, & 48.25) \\
\hline Female & 2418 & 53.23 & (51.75, & 54.70) \\
\hline \multicolumn{5}{|l|}{ Race/Ethnicity } \\
\hline NH White & 2237 & 55.38 & (53.83, & 56.92) \\
\hline NH Black & 592 & 12.36 & (11.42, & 13.36) \\
\hline Hispanic & 1110 & 19.42 & $(18.28$ & 20.61) \\
\hline NH Other & 474 & 12.84 & (11.84, & 13.92) \\
\hline \multicolumn{5}{|l|}{ Degree program } \\
\hline Technical / vocational & 181 & 3.63 & (3.04, & 4.33) \\
\hline 2-year degree & 1020 & 21.70 & (20.16, & 23.33) \\
\hline 4-year degree & 2850 & 65.41 & $(63.55$ & 67.21) \\
\hline Graduate / professional & 295 & 7.87 & $(6.92$, & 8.93) \\
\hline Other type of degree & 58 & 1.40 & $(0.94$, & 2.07) \\
\hline \multicolumn{5}{|l|}{ Region } \\
\hline Northeast & 768 & 20.62 & $(19.00$ & 22.34) \\
\hline Midwest & 988 & 21.14 & (19.57, & 22.80) \\
\hline South & 1596 & 34.09 & (32.24, & 35.99) \\
\hline West & 1061 & 24.15 & (22.39, & 26.01) \\
\hline \multicolumn{5}{|c|}{ Cigarette smoking in the past 12 months } \\
\hline Yes & 1024 & 26.69 & $(24.75$, & 28.72) \\
\hline No & 2770 & 73.31 & (71.28, & 75.25) \\
\hline \multicolumn{5}{|c|}{ Alcohol drinking in the past 12 months } \\
\hline Yes & 3055 & 77.11 & (73.95, & 79.99) \\
\hline No & 1118 & 22.89 & $(20.01$, & 26.05) \\
\hline \multicolumn{5}{|l|}{ Ever used marijuana } \\
\hline Yes & 2235 & 49.09 & (45.95, & 52.24) \\
\hline No & 2178 & 50.91 & (47.76, & 54.05) \\
\hline \multicolumn{5}{|l|}{ Ever used drugs a } \\
\hline Yes & 1154 & 25.00 & (23.17, & 26.92) \\
\hline No & 3259 & 75.00 & (73.08, & 76.83) \\
\hline \multicolumn{5}{|l|}{ Past year internalizing problems ${ }^{\mathrm{b}}$} \\
\hline No/low & 2193 & 49.94 & (48.06, & 51.81) \\
\hline Moderate & 1098 & 25.36 & (23.79, & 27.00) \\
\hline High & 1106 & 30.42 & (23.21, & 26.26) \\
\hline \multicolumn{5}{|l|}{ Past year externalizing problems ${ }^{b}$} \\
\hline No/low & 1921 & 49.63 & (47.77, & 51.48) \\
\hline Moderate & 1277 & 34.23 & (32.52, & 36.00) \\
\hline High & 621 & 16.13 & $(14.85$ & 17.51) \\
\hline
\end{tabular}

Note: $\quad$ a. Including misuse of prescription drugs (i.e. Ritalin ${ }^{\circledR}$ or Adderall@; painkillers, sedatives, or tranquilizers; other drugs (cocaine or crack, stimulants (i.e. methamphetamine or speed), heroin, inhalants, solvents, and hallucinogens)

b. Past year internalizing and externalizing problems were assessed using the Global Appraisal of Individual Needs Short Screener (GAIN-SS) categorized as low (0-1 symptoms), moderate (2-3 symptoms), and high (4 symptoms for internalizing problems or $\geq 4$ symptoms for externalizing problems) levels

Table 2 presents the prevalence of lifetime, also known as “ever", past 12-months, and current ENP use by gender. About $50 \%$ of men and $40 \%$ of women reported they used ENPs in their lifetime. Lifetime use, past 12-months use, and past 30-day use prevalence among men was 
significantly higher when compared to women. The largest difference in prevalence of current ENP use between men and women was among non-Hispanic Whites at $10.9 \%$.

Table 2. Prevalence of electronic nicotine products users among college students in the US, 2017, by gender

\begin{tabular}{|c|c|c|c|c|}
\hline & Male & Female & & s. Female \\
\hline & $n_{M^{a}} P_{M}^{b}(\%, 95 \% C I)$ & $n_{F}^{c} \quad P_{F}^{d}(\%, 95 \% C I)$ & P-Value ${ }^{e}$ & Prevalence Ratio ${ }^{f}$ \\
\hline Ever User & $197550.2(46.5,54.0)$ & $238941.6(38.4,44.8)$ & $<.001$ & $1.11(1.04,1.21)$ \\
\hline Past 12 Month Users & $175732.2(29.2,35.4)$ & $206822.6(20.3,25.0)$ & $<.001$ & $1.46(1.25,1.69)$ \\
\hline Current Users & $175819.7(17.5,22.1)$ & $206911.1(9.6,12.9)$ & $<.001$ & $1.82(1.51,2.19)$ \\
\hline \multicolumn{5}{|l|}{ Race/Ethnicity } \\
\hline NH White & $92722.3(19.1,25.7)$ & $104311.3(8.9,14.3)$ & $<.001$ & \\
\hline NH Black & $21516.4(11.5,22.7)$ & $9.1(5.9,13.8)^{g}$ & 0.036 & \\
\hline Hispanic & $43916.4(12.4,21.4)$ & $52511.3(8.2,15.2)$ & 0.073 & \\
\hline NH Other & $17716.1(10.4,24.1)^{g}$ & $21312.2(8.5,17.3)$ & 0.336 & \\
\hline
\end{tabular}

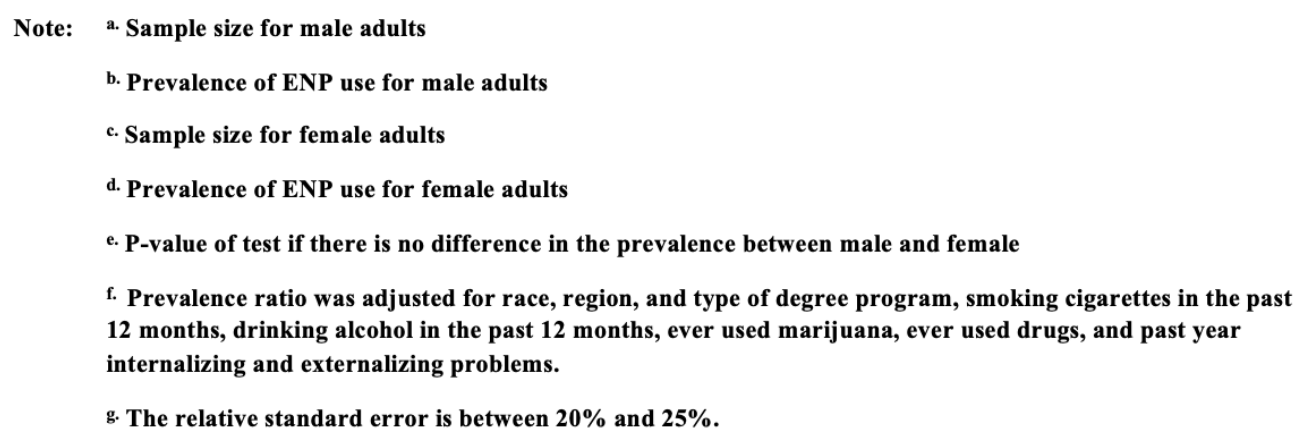

Figure 1 shows the proportion of flavored ENPs users among lifetime users when they first started using ENPs stratified by gender and race/ethnicity. The proportions were high, $86.5 \%$ for men and $89.1 \%$ for women, and were similar between men and women across all racial and ethnic groups. 


\section{Figure 1 Proportion of Flavored ENP Used When Lifetime Users First Started Among College Students in the US, 2017, by Gender and Race/Ethnicity}

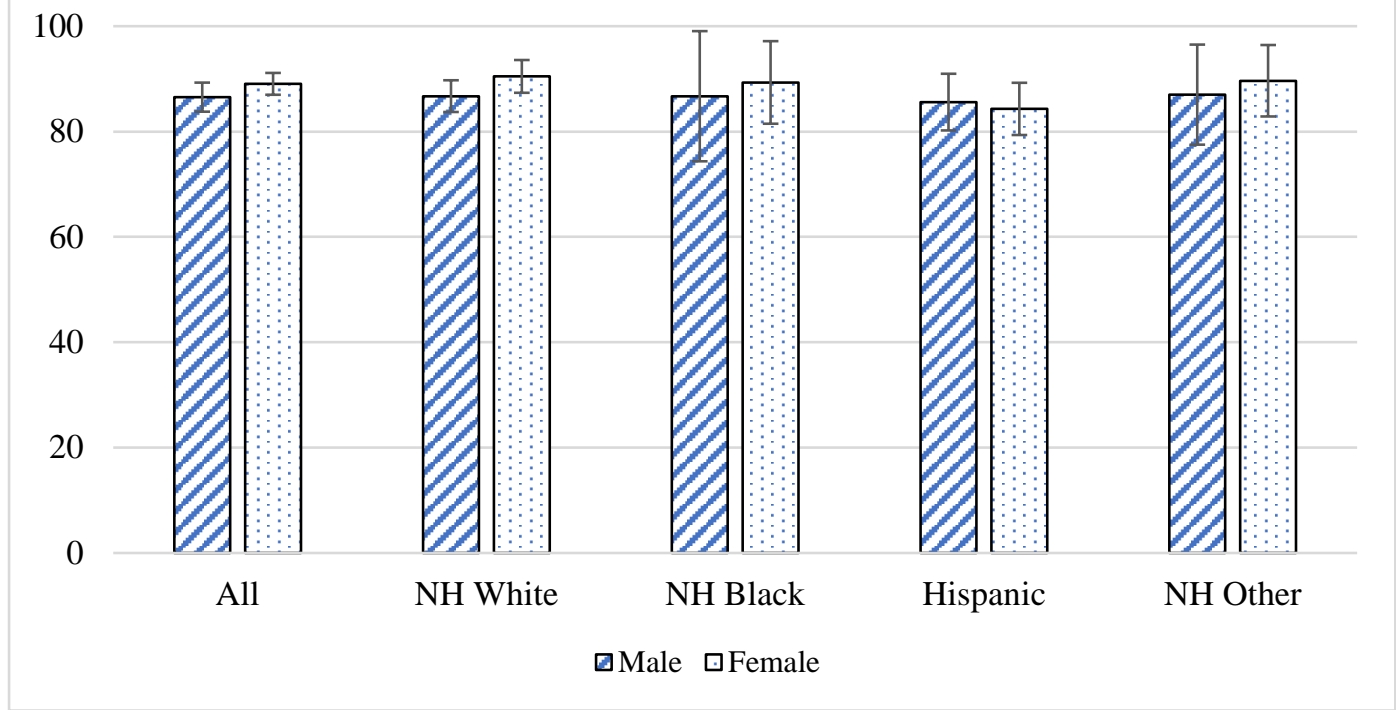

Table 3 presents the reasons for use of ENPs among past 30-day users. The most popular reason ( $76.2 \%$ in men, $81.4 \%$ in women) was that the e-liquid came in flavors users liked. Other popular reasons were that users considered ENPs as less harmful to them than cigarettes (75.2\% for men, $67.7 \%$ for women) and to people around them than cigarettes (68.5\% for men, $69.0 \%$ for women). Men also reported at a higher proportion (7.5\% higher than women) that they used ENPs because they could use ENPs in places where cigarettes were not allowed. After adjusting for covariates, only the difference in proportion of misconception that using ENPs might be less harmful to users than cigarettes between men and women remained significant. 
Table 3. Reasons of using electronic nicotine products among currently or formerly established, current experimental, or non-current 18-24 college student users in the US, 2017, by gender

\begin{tabular}{|c|c|c|c|}
\hline & Male & Female & Male vs. Female \\
\hline & $n_{M^{a}} P_{M}^{b}(\%, 95 \% C I)$ & $n_{F}{ }^{c} \quad P_{F}^{d}(\%, 95 \% C I)$ & $\begin{array}{l}\text { Prevalence Ratio } \\
(95 \% \text { CI })\end{array}$ \\
\hline Affordable & $58944.0(39.1,49.0)$ & $46042.3(36.7,48.2)$ & $0.95(0.78,1.17)$ \\
\hline $\begin{array}{l}\text { Allowed ENP while not smoking } \\
\text { cigarettes }\end{array}$ & $59054.1(49.0,59.1)$ & $46246.6(41.6,51.6)^{f}$ & $1.16(0.97,1.40)$ \\
\hline $\begin{array}{l}\text { Less harmful to me than smoking } \\
\text { cigarettes }\end{array}$ & $59075.2(71.5,78.5)$ & $46367.7(62.2,72.8)^{f}$ & $1.19(1.06,1.33)$ \\
\hline $\begin{array}{l}\text { Less harmful to people around } \\
\text { me than cigarettes }\end{array}$ & $59068.5(63.8,72.9)$ & $46669.0(63.3,74.1)$ & $1.02(0.89,1.18)$ \\
\hline E-liquid having flavors I like/liked & $58876.2(72.2,79.8)$ & $46381.4(77.6,84.7)^{f}$ & $0.93(0.86,1.02)$ \\
\hline Helping quit smoking cigarettes & $27655.3(48.0,62.3)$ & $16657.1(48.2,65.6)$ & $0.96(0.79,1.17)$ \\
\hline Don't smell & $58856.8(52.1,61.4)$ & $46555.7(49.3,61.9)$ & $0.98(0.84,1.15)$ \\
\hline $\begin{array}{l}\text { More acceptable to non-tobacco } \\
\text { users }\end{array}$ & $58421.1(17.7,25.1)$ & $46416.1(12.0,21.2)$ & $1.06(0.72,1.54)$ \\
\hline
\end{tabular}

\footnotetext{
Note: a. Sample size for male adults

b. Proportion of "yes" to the question for male adults

c. Sample size for female adults

d. Proportion of "yes" to the question for female adults

e. Prevalence ratio was adjusted for race, region, and type of degree program, smoking cigarettes in the past 12 months, drinking alcohol in the past 12 months, ever used marijuana, ever used drugs, and past year internalizing and externalizing problems.

f. P-value $<0.05$ compared with male
}

Table 4 presents susceptibility to ENPs among college student never users by gender. Men were more curious about ENPs than women (28.1\% for men, $23.2 \%$ for women). However, men and women were similarly susceptible to ENP use (35.5\% for men, 32.0\% for women, $\mathrm{p}=$ 0.133). This similarity was present across all racial/ethnic groups. The highest proportion of susceptibility to ENP use was among non-Hispanic White men (38.1\%) and Hispanic men $(37.4 \%)$. 
Table 4. Susceptibility to ENPs among college students ENP never users

in the US, 2017, by gender

\begin{tabular}{|c|c|c|c|c|c|c|}
\hline & \multicolumn{2}{|r|}{ Male } & \multicolumn{2}{|r|}{ Female } & \multicolumn{2}{|c|}{ Male vs. Female } \\
\hline & $\mathbf{n}_{M^{a}}$ & $\mathrm{P}_{\mathrm{M}}^{\mathrm{b}}(\%, 95 \% \mathrm{CI}$ & $\mathbf{n}_{\mathbf{F}}{ }^{\mathrm{e}}$ & $P_{F}^{d}(\%, 95 \% C I)$ & $\mathbf{P}_{M^{-}} \mathbf{P}_{F}(\%)^{e}$ & P-Value ${ }^{f}$ \\
\hline Curious about using ENPg & 950 & $28.1(24.6,31.9)$ & 1346 & $623.2(20.7,25.9)$ & 4.9 & 0.029 \\
\hline Think to try an ENP soon ${ }^{h}$ & 953 & $16.6(13.5,20.2)$ & 1350 & 0 13.4 (11.2, 15.8) & 3.2 & 0.116 \\
\hline $\begin{array}{l}\text { Would try if best friends were } \\
\text { to offer an ENP }\end{array}$ & 950 & $25.9(22.6,29.5)$ & 1344 & $421.2(17.9,25.0)$ & 4.6 & 0.064 \\
\hline Susceptibility All & 950 & $35.9(32.1,39.9)$ & 1343 & $332.0(28.7,35.4$ & 3.9 & 0.133 \\
\hline \multicolumn{7}{|l|}{ Race/Ethnicity } \\
\hline NH White & 459 & $38.1(32.7,43.8)$ & 664 & $32.0(26.7,37.8)$ & 6.1 & 0.128 \\
\hline NH Black & 129 & $23.4(15.7,33.4)$ & 212 & $31.8(25.2,39.2)$ & -8.4 & 0.149 \\
\hline Hispanic & 242 & $37.4(30.3,45.1)$ & 330 & $31.9(26.2,38.2)$ & 5.5 & 0.260 \\
\hline NH Other & 120 & $36.7(25.4,49.8)$ & 137 & $32.0(22.4,43.5)$ & $\underline{4.7}$ & $\underline{0.579}$ \\
\hline
\end{tabular}

Note: a. Sample size for male adults

b. Proportion of "yes" to the question for male adults

c. Sample size for female adults

d. Proportion of "yes" to the question for female adults

e. Difference in proportion of "yes" to the question between male adults and female adults

f. $P$-value of test if there is no difference in the proportion between male and female

g. "Very curious", "Somehow curious", or "A little curious" was grouped to "Yes" to the question.

h. "Definitely yes", "Probably yes", or "Probably not" was grouped to "Yes" to the question. 
Table 5 presents the association between current ENP use or past 12-months ENP use and demographic variables and risk factors. Male students were more likely than female students to use ENPs both in the past 30-days and the past 12-months. Type of degree was significantly associated with ENP use as well. Relative to graduate students, students in other degree programs were 2 to 3 times more likely to have used ENPs in the past 30-days and the past 12months. Both individuals who had smoked cigarettes in the past 12-months and those who had drank alcohol in the past 12-months were more likely to use ENPs than those who had not used either, respectively. Ever users of marijuana showed a statistically higher likelihood to use ENPs when compared to never users $(\mathrm{p}<0.001)$. Compared to those with no/low past year externalizing problems, those in the "high" level category were more likely to be current ENP users $(\mathrm{p}<0.001)$ or report ENP use in the past 12 -months $(\mathrm{p}<0.001)$ 
Table 5. Multivariable analysis of current use and past 12 months use of ENP among college students in the US, 2017

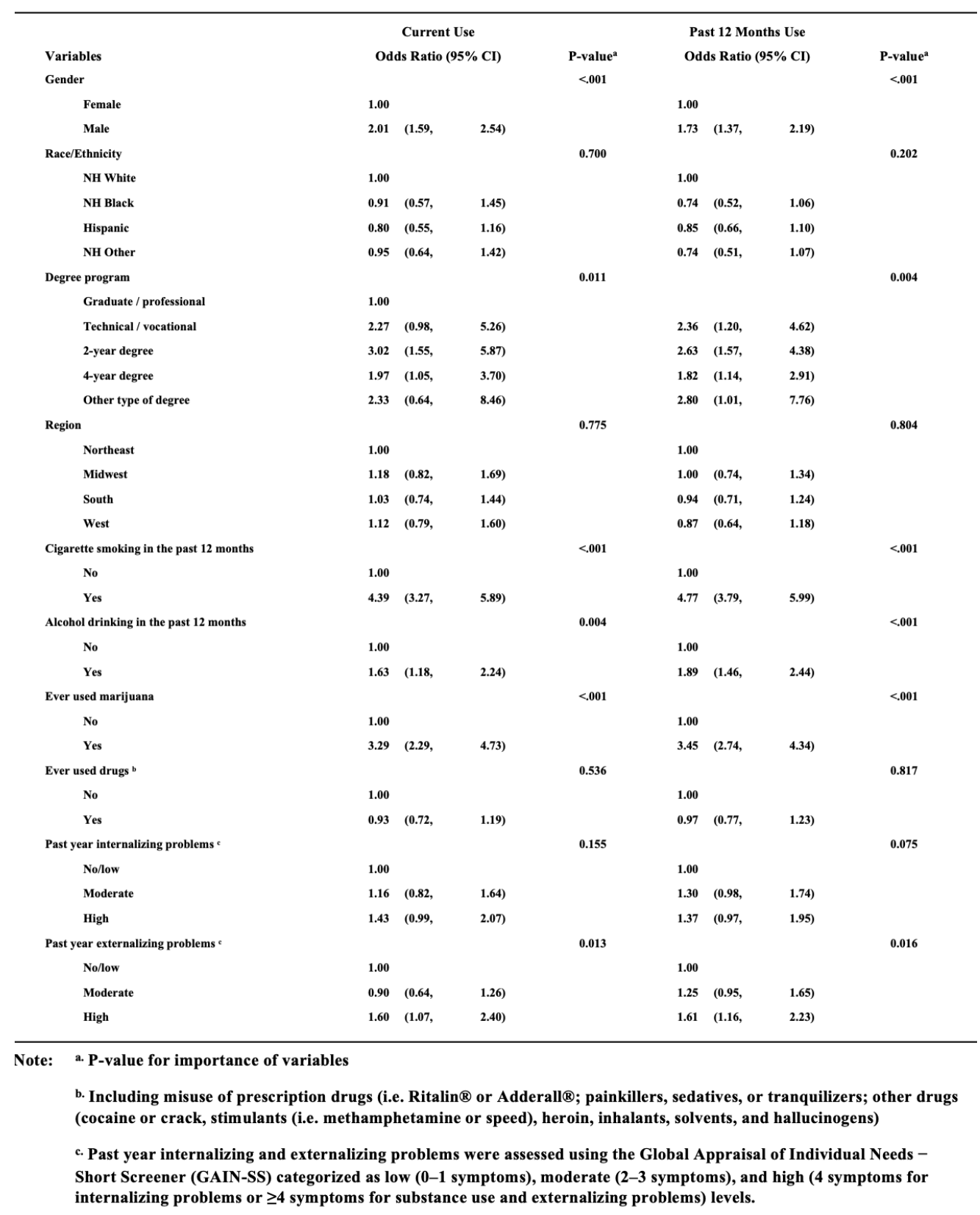

\section{Discussion}

The study results from the PATH Wave 4 survey demonstrated that, among young adults ages 18-24 who were enrolled in a degree program, men nationwide were significantly more likely to report lifetime, past 12-months, and current use of electronic nicotine products than 
women. These patterns persisted after adjusting for sociodemographic variables, substance use, and mental health. Additionally, disparity of men-women differences in ENPs use was observed. Data also found that 80-90\% of U.S. college student ENP users began use with flavored ENPs, across genders and racial/ethnic groups. Furthermore, the highest reasons for use among U.S. college students were the misconceptions that ENP use was less harmful to the user than smoking cigarettes and that the e-liquid came in flavors the user liked. Findings that both cigarette smoking in the past 12-months and ever use of marijuana were highly associated with the use of ENP, respectively, suggest that nicotine cessation programs for college students need to apply comprehensive measures, such as taking other substance use, into account. In terms of mental health, past year externalizing problems were also associated with the use of ENPs, proposing a likely need for available counseling services.

Strikingly, about $50 \%$ of male and about $40 \%$ of female college students had used ENPs in their lifetime in the United States. In 2017, $20 \%$ of male college students and $10 \%$ of female college students reported current use of ENPs. When compared to two previous studies using nationally representative samples that both reported use of high use of ENPs among young adults (Mirbolouk et al, 2018; Rostron et al., 2020), findings in this survey are in line with lifetime users aged 18-24 years (50.7\%) (Rostron et al., 2020) but are higher than the prevalence of current use of e-cigarettes reported in the 2016 study (9.2\% for men and $2.5 \%$ for women, aged 18-24 years) (Mirbolouk et al, 2018). This difference may be due to latter study utilizing data from the U.S. Behavioral Risk Factor Surveillance System (BRFSS), where use of ENPs is not a key variable. The secondary data analysis might, therefore, affect its estimation (Keicolt \& Nathan, 1985).

The findings add to the evidence that, nationally, flavored ENPs serve as starter products to ENP users among college students across gender and race/ethnicity with no exception.

Preventing youth and young adults from using flavored ENPs may help reduce ENP use among college students in the future.

Both male and female students reported a high misconception that the use of ENPs is less harmful to users than smoking cigarettes. Although female students reported a significantly higher proportion of ENP use due to the fact that the e-liquid came in flavors compared to male students, the proportion of ENP use because of flavored e-liquid was high in both groups. The 
current study addresses evidence that can be used in college health education programs related to nicotine dependence and in new legislation with regard to flavor. As women were more likely to become nicotine dependent than men (Smith et al., 2016), these findings have the potential impact for guidelines concerning use of ENPs among college women.

In this investigation, $36 \%$ of male and $32 \%$ of female college/university students who were naïve to nicotine products were susceptible to ENP use. This could be associated with the tobacco industry's aggressive marketing strategy and lack of effective health education concerning ENPs and other substance use for young adults (Pierce et al., 2017). Preventing college students from using ENPs is crucial, given that ENP use can lead to high susceptibility to conventional cigarette smoking (Wang et al., 2018). Prevention will require the implementation of comprehensive strategies, which should begin before entering a degree program. Parents and educational leaders can advise youth about the dangers of nicotine and discourage use in any form. However, colleges and universities need more targeted measures of intervention programs taking advantage of college/university education (Berg et al, 2020; Lee et al, 2010), as institutional intervention is effective for behavioral changes (Emmons, 2000).

This study has limitations. First, due to the use of self-reported data, measurement errors such as reporting bias and recall bias might have confounded the findings. Also, unmeasured factors might have influenced the associations found in the present study. Despite these limitations, the present study is the first attempt that investigated use of ENPs among college students nationwide.

\section{Conclusion}

In conclusion, prior to nation-wide efforts to curb popularity of ENPs in 2019, gender differences in use and reasons for use did exist, while both males and females who were naïve to ENPs were susceptible for use. This information, as indicated by the data, can be used as a baseline against which public policymakers can measure efficacies of recently implemented restrictions on ENPs. The data show the need that comprehensive health promotion programs should be implemented into tobacco-use prevention education among colleges/universities. Because high reported levels of externalizing problems related to mental health and use of other substances was significantly correlated with use of ENPs, it is necessary to have therapy or substance abuse education available. Using these strategies and related health promotion programs, ENPs use among college/university students can be reduced for both male and female 
students. The results of this study can help guide public health policy and improve existing health promotion programs to prevent ENPs use within the United States.

\section{References}

Berg, C. J., Yang, Y. T., Pratt-Chapman, M. L., Douglas Evans, W., Cupertino, A. P., Horn, K., ... \& Tercyak, K. P. (2020). Campus tobacco control policies and cessation interventions in college students: a commentary calling for research and action to address tobacco-related health disparities. Translational behavioral medicine. doi: 10.1093/tbm/ibaa083.

Bullen, C., McRobbie, H., Thornley, S., Glover, M., Lin, R., \& Laugesen, M. (2010). Effect of an electronic nicotine delivery device (e cigarette) on desire to smoke and withdrawal, user preferences and nicotine delivery: randomised cross-over trial. Tobacco control, 19(2), 98-103. doi: $10.1136 /$ tc. 2009.031567

Butler, K. M., Ickes, M. J., Rayens, M. K., Wiggins, A. T., \& Hahn, E. J. (2015). Polytobacco use among college students. Nicotine \& Tobacco Research, 18(2), 163-169. doi: 10.1093/ntr/ntv056.

Conway, K. P., Green, V. R., Kasza, K. A., Silveira, M. L., Borek, N., Kimmel, H. L., ... \& Compton, W. M. (2017). Co-occurrence of tobacco product use, substance use, and mental health problems among adults: Findings from Wave 1 (2013-2014) of the Population Assessment of Tobacco and Health (PATH) Study. Drug and alcohol dependence, 177, 104-111.doi: 10.1016/j.drugalcdep.2017.03.032.

Cross, S. J., Linker, K. E., \& Leslie, F. M. (2017). Sex-dependent effects of nicotine on the developing brain. Journal of neuroscience research, 95(1-2), 422-436. doi: 10.1002/jnr.23878.

Dennis, M., Feeney, T., Stevens, L., \& Bedoya, L. (2006). Global Appraisal of Individual Needs-Short Screener (GAIN-SS): Administration and scoring manual for the GAIN-SS version 2.0.3. http://www.chestnut.org/LI/gain/GAIN_SS/index.htmlBloomington, IL: Chestnut Health Systems.

Emmons, K. M. Health behaviors in a social context. In Social Epidemiology, ed by Berkman, L. E. and Kawachi, I. 2000, Oxford University Press.

Friedman, A. S. (2020). Tobacco-21 laws: insights from the US experience. Nicotine and Tobacco Research, 22(7), 1254-1255. doi: 10.1093/ntr/ntz181.

Kiecolt, K. J., Nathan, L. E. (1985). Secondary analysis of survey data. Sage Publications.

Ickes, M., Hester, J. W., Wiggins, A. T., Rayens, M. K., Hahn, E. J., \& Kavuluru, R. (2020). Prevalence and reasons for Juul use among college students. Journal of American College Health, 68(5), 455-459. doi: 10.1080/07448481.2019.1577867.

King, A. C., Smith, L. J., McNamara, P. J., Matthews, A. K., \& Fridberg, D. J. (2015). Passive exposure to electronic cigarette (e-cigarette) use increases desire for combustible and e-cigarettes in young adult smokers. Tobacco control, 24(5), 501-504. doi: 10.1136/tobaccocontrol-2014-051563 
Lee, J. G., Goldstein, A. O., Kramer, K. D., Steiner, J., Ezzell, M. M., \& Shah, V. (2010). Statewide diffusion of 100\% tobacco-free college and university policies. Tobacco control, 19(4), 311-317. doi: 10.1136/tc.2009.032888.

Li, J., Haardörfer, R., Vu, M., Windle, M., \& Berg, C. J. (2018). Sex and sexual orientation in relation to tobacco use among young adult college students in the US: a cross-sectional study. BMC public health, 18(1), 1-11. doi: 10.1186/s12889-018-6150-x.

Mirbolouk, M., Charkhchi, P., Kianoush, S., Uddin, S. I., Orimoloye, O. A., Jaber, R., ... \& Blaha, M. J. (2018). Prevalence and distribution of e-cigarette use among US adults: behavioral risk factor surveillance system, 2016. Annals of internal medicine, 169(7), 429-438. doi:10.7326/M17-3440

Murthy, V. H. (2017). E-cigarette use among youth and young adults: a major public health concern. JAMA pediatrics, 171(3), 209-210. doi: 10.1001/jamapediatrics.2016.4662

Newcombe, K. V., Dobbs, P. D., Oehlers, J. S., Dunlap, C. M., \& Cheney, M. K. (2021). College Students' Reasons for Using JUULs. American Journal of Health Promotion, 0890117121992292. doi: 10.1177/0890117121992292.

Pierce, J. P., Sargent, J. D., White, M. M., Borek, N., Portnoy, D. B., Green, V. R., ... \& Messer, K. (2017). Receptivity to tobacco advertising and susceptibility to tobacco products. Pediatrics, 139(6). doi: 10.1542/peds.2016-3353.

Pogun, S., Yararbas, G., Nesil, T., \& Kanit, L. (2017). Sex differences in nicotine preference. Journal of neuroscience research, 95(1-2), 148-162. doi: 10.1002/jnr.23858.

Roberts, M. E., Keller-Hamilton, B., Ferketich, A. K., \& Berman, M. L. (2020). Juul and the upsurge of e-cigarette use among college undergraduates. Journal of American College Health, 1-4.doi: $10.1080 / 07448481.2020 .1726355$.

Rostron, B. L., Cheng, Y. C., Gardner, L. D., \& Ambrose, B. K. (2020). Prevalence and reasons for use of flavored cigars and ends among US youth and adults: Estimates from wave 4 of the PATH study, 2016-2017. American journal of health behavior, 44(1), 76-81. doi:10.5993/AJHB.44.1.8.

Smith, P. H., Bessette, A. J., Weinberger, A. H., Sheffer, C. E., \& McKee, S. A. (2016). Sex/gender differences in smoking cessation: a review. Preventive medicine, 92, 135-140. doi: 10.1016/j.ypmed.2016.07.013.

Smith, P. H., Ward, R. M., Bartoszek, L. A., \& Branscum, P. W. (2020). College students' patterns of electronic nicotine delivery system use and other substance use. Journal of American College Health, 1-7. doi: 10.1080/07448481.2020.1841210.

US Department of Health and Human Services. (2014). The health consequences of smoking — 50 years of progress: a report of the Surgeon General.

U.S. Department of Health and Human Services. E-Cigarette Use Among Youth and Young Adults: A Report of the Surgeon General. Atlanta, GA: US Department of Health and Human Services, Centers for Disease Control and Prevention, National Center for Chronic Disease Prevention and Health Promotion, Office on Smoking and Health; 2016. http://www.ncbi.nlm.nih.gov/books/NBK179276/. 
United States Department of Health and Human Services. National Institutes of Health. National Institute on Drug Abuse, and United States Department of Health and Human Services. Food and Drug Administration. Center for Tobacco Products. Population Assessment of Tobacco and Health (PATH) Study [United States] Public-Use Files. Inter-university Consortium for Political and Social Research [distributor], 2019-11-21. https://doi.org/10.3886/ICPSR36498.v10.

Wang TW, Tynan MA, Hallett C, et al. Smoke-Free and Tobacco-Free Policies in Colleges and Universities - United States and Territories, 2017. MMWR Morb Mortal Wkly Rep 2018;67:686-689. http://dx.doi.org/10.15585/mmwr.mm6724a4external icon. 